\title{
Ganglia removal and photically driven activity in the earthworm (L.terrestris)'
}

HARMON V. S. PEEKE, MICHAEL J. HERZ AND EVERETT J. WYERS

UNIVERSITY OF SOUTHERN CALIFORNIA

\begin{abstract}
This experiment investigates the effect of removing the anterior ganglia on the earthworm's locomotor response to light. Ss with their five anterior segments amputated, Ss with both pairs of ganglia surgically isolated, and Ss with only the supraoeosophageal ganglia removed showed increased locomotor activity during a period of exposure to intermittent light as compared with periods of darkness. Normal and sham operated Ss also showed increased reactivity to light but were significantly less reactive than two of the operated groups.

Problem
\end{abstract}

A number of studies of learning in earthworms have used light as a stimulus (e.g., Wayner \& Zellner, 1958; Ratner \& Miller, 1959; Ratner, 1962). Among these, several have investigated the role of the anterior ganglia in conditioning. Using intense light as the UCS, Ratner \& Miller (1959) and Ratner (1962) conditioned worms deprived of their anterior five segments (including both pairs of ganglia) and compared them to intact Ss. During a similar study (Herz et al, 1964) we observed increased reactivity in worms from which the supraoesophageal ganglia alone had been removed. Such animals showed more conditioned and unconditioned responsiveness than did normal animals; i.e., the surgically modified animals were more active throughout the conditioning procedures, particularly during the brief, intense photic UCS.

The present study was undertaken to investigate the effect of surgical removal of the anterior ganglia on reactivity to intense light. In addition, a group of Ss was included that had the anterior five segments amputated after the manner of Ratner \& Miller (1959) and Ratner (1962)。

\section{Method}

Fifty earthworms (L. terrestris) were used in this study. The Ss were run and maintained at room temperature (approx. $24^{\circ} \mathrm{C}$ ).

The apparatus was a modification of the Ratner \& Miller (1959) conditioning apparatus. It consisted of a clear plastic tube $(9 \mathrm{~mm}$ inside diameter and $64 \mathrm{~cm}$ long) forming a circular runway. The tube was ventilated with $1 \mathrm{~mm}$ holes placed at $1 \mathrm{~cm}$ intervals along the top. A white circular pathway directly beneath the tube was divided into 18 equal sections by black lines placed 20 degrees apart. Photic stimulation was provided by a No. 2 (G。E.) photoflood bulb in a reflector mounted $46 \mathrm{~cm}$ above the base. The bulb produced approximately $850 \mathrm{ft}$-candles of illumination after passing through the top surface of the tube. A 25-w red bulb provided general room illumination.

The Ss were divided into five groups of 10 each: a normal group (N), a sham-operated group (S), a gangliectomized group in which only the supraoesophageal ganglia were surgically removed (GE), a gangliotomized group in which the ventral nerve cord was severed just posterior to the suboesophageal ganglia (GO), and a group with supra- and suboesophageal ganglia removed by amputation of the anterior five segments (GA). Groups $\mathrm{S}, \mathrm{GE}$, and $\mathrm{GO}$ were operated on $24 \mathrm{hr}$. prior to the experimental session. Group GA Ss, to replicate Ratner \& Miller (1959) and Ratner's (1962) methods, were operated on $20 \mathrm{~min}$. before the experimental session.

The Ss in groups GE, GO, and S were anesthetized in $0.5 \%$ chloretone solution for $2 \mathrm{~min}$. or until all movement ceased. Ss in group GE were incised on the dorsal surface between segments 2 and 5 . The supraoesophageal ganglia were lifted with fine forceps and the circumoesophageal commissures severed freeing the ganglia for removal. Group GO Ss were incised on the ventral surface between segments 3 and 6 . The ventral nerve cord was then transected just posterior to the suboesophageal ganglia, isolating both pairs of ganglia. The Ss in group $\mathrm{S}$ were incised on the dorsal surface between segments 2 and 5, with no further tissue insult. Group GA Ss had their anterior five segments amputated with a sharp razor blade and were placed directly in the observation tube for the pre-experimentation $20 \mathrm{~min}$. dark adaptation period. The Ss in group $\mathrm{N}$ were subjected to no surgical treatment.

Twenty-four hr. after surgery each S (except GA Ss which were treated as outlined above) was allowed to crawl into one end of the plastic tube which had just previously been moistened with $0.6 \mathrm{cc}$ of water. Each $\mathrm{S}$ was then given a $20 \mathrm{~min}$. dark adaptation period under dim red illumination.

The experimental session was divided into three periods, each lasting $300 \mathrm{sec}$. The first period (prestimulation) was an observation period without external stimulation. The $\mathrm{S}$ was observed and each crossing of a line by either forward or backward movement was recorded. The second period (stimulation) followed immediately. This period was divided into 20 15-sec. intervals, which approximated the intertrial interval used in our previous conditioning studies (e.g., Herz et al, 1964). At the beginning of each of these 15-sec. periods the photic stimulation was presented for $2 \mathrm{sec}$. Again, movements across grid lines were 
recorded. After the conclusion of the stimulation period, $1 \mathrm{~min}$. was interpolated before recording movements during the third period (post-stimulation). The post-stimulation period was without external stimulation.

\section{Results}

An analysis of variance was performed for the five groups across the three stimulation periods. Significant F ratios demonstrated a reliable groups effect, stimulation effect, and interaction between groups and stimulation period $(p<.005$ in all three cases).

Three Duncan's Multiple Range Tests were used for comparisons of means within each stimulation period. Comparisons of means for the pre-stimulation period indicated that the mean for group GO was significantly greater than the means for groups $\mathrm{N}, \mathrm{S}$, and GA $(p<.05$ in all three cases; see Fig. 1$)$.

Comparisons of means for the stimulation period demonstrated differences between groups $\mathrm{N}$ and GO $(p<.05)$; groups $N$ and GE $(p<.001)$; groups $S$ and GO $(p<.01)$; and groups $S$ and $G E(p<.001)$. In all of these cases the means for the operated groups (GO and GE) were higher than the means for the normal (N) and sham-operated (S) groups. Further, the mean for group GE was significantly higher than the mean for group GA $(p<.005)$. Group GA did not differ significantly from the normal or sham-operated groups, nor from group GO. Groups GE and GO had the highest response levels and groups $\mathrm{N}$ and $\mathrm{S}$ had the lowest.

Comparison of means for the post-stimulation period showed group GA to be significantly less active than group GE and group $\mathrm{S}(\mathrm{p}<.05$ in both cases). Group GA was also less active than group GO $(.10<\mathrm{p}<.05)$.

\section{Diseussion}

The results clearly indicate that removal of the supraoesophageal ganglia (GE), and the isolation of both the supra- and suboesophageal ganglia (GO), greatly increases reactivity to bright light. The absence of difference between the reactivity of normal Ss (N) and that of sham-operated Ss (S) indicates that the increased reactivity in the other groups is the result neither of the anesthesia nor of the surgical incision. The effect of amputation of the first five segments is somewhat ambiguous. Considering the central nervous system deficit alone, ganglia-amputated Ss (GA) would be expected to be just as reactive as gangliotomized Ss (GO), since the animals in both groups were functionally without both pairs of ganglia. Although groups GA and GO did not differ significantly in mean reactivity, group GO differed significantly from normal (N) and sham-operated Ss (S), while group GA Ss did not. One interpretation of this trend toward less reactivity in the ganglia-amputated group is that the surgical procedure (which was carried out only $20 \mathrm{~min}$. prior to experimentation in this group) produced a post-surgical depression of responsiveness.

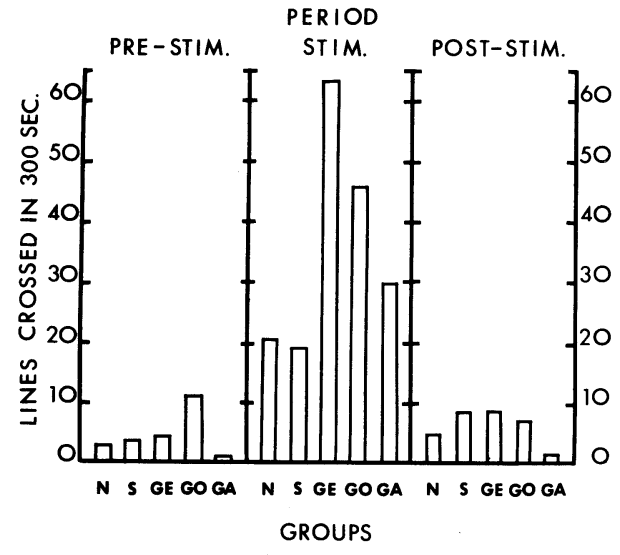

Fig. 1. Mean number of line crossings in three successive stimulation periods (pre-stimulation, stimulation, and post-stimulation) by three operated groups, gangliectomized (GE), gangliotomized (GO), and ganglia-amputated (GA), a sham-operated group (S), and a normal group $: \mathbf{N}$ ).

Several investigators have reported that surgical interference with the neural connections of the supraoesophageal ganglia results in reversal of the normal withdrawal response to light (e.g., Hess, 1924; Ratner \& Miller, 1959). In addition to increased locomotor activity, reversal of the normal contraction response to bright light stimulation in gangliectomized, gangliotomized, and ganglia-amputated Ss was observed in the present study. It was also noted that forward locomotion in the gangliectomized Ss was well coordinated and rhythmic, whereas movement in the gangliotomized and ganglia-amputated Ss was jerky and arhythmic. These observations are consistent with the interpretation that the supraoesophageal ganglia contain inhibitory mechanisms modulating locomotion and contolling direction of movement in response to photic stimulation.

\section{References}

Herz, M. J., Peeke, H. V. S., \& Wyers, E. J. The effect of ganglia removal and partial reinforcement on conditioning and extinction in the earthworm Amer. Psychologist, 1964, 19, 502. (Abstract)

Hess, W. N. Reactions to light in the earthworm, Lumbricus terrestris. L. J. Morph., 1924, 39, 517-542.

Ratner, S. C. Conditioning of decerebrate worms, Lumbricus terrestris. J. comp. physiol. Psychol., 1962, 55, 174-177.

Ratner, S. C., \& Miller, K. R. Effects of spacing of training and ganglia removal on conditioning in earthworms. J. comp. physiol. Psychol., 1959, 52, 667-672.

Wayner, M. J., \& Zellner, D. K The role of the suprapharyngeal ganglion in spontaneous alternation and negative movements in Lumbricus terrestris L. J. comp. physiol. Psychol., 1958, 51, 282-287.

Wyers, E. J., Peeke, H. V. S., \& Herz, M. J. Partial reinforcement and resistance to extinction in the earthworm. J. comp. physiol. Psychol., 1964, 57, 113-116.

\section{Note}

1. This study w:ts supported in part by Research Grant G-18891 from the National Science Foundation and by Public Health Service Fellowship 5 F1-MH-22,269 (to M. J. Herz) from the National Institute of Mental Health. 